\title{
Achegas para a História dos Mestres de Capela do Rio de Janeiro Colonial
}

\author{
Maurício Dottori
}

Poucas notícias se conhecem sobre os primeiros mestres de capela do Rio de Janeiro. Não existem trabalhos publicados até hoje, como há, por exemplo, sobre os de Salvador da Bahia'. Sabemos que Antônio Nunes de Sequeira ocupava o posto na catedral do Rio de Janeiro em 1743, porque dele há uma carta na apresentação do tratado Escola de Canto e Órgão, do então mestre de capela de Salvador, Caetano de Mello Jesus. Sequeira, nascido no Rio em 2 de abril de 1701 e morto em 1759 foi, segundo Sacramento Blake, homem culto e, ao mesmo tempo que mestre de capela da Catedral, pertenceu à Academia dos Selectos, foi reitor do seminário diocesano de São José e examinador sinodal ${ }^{2}$. Sabemos que em 1789 morreu João Lopes Ferreira e foi substituído por José Maurício Nunes Garcia, sem dúvida o maior e o mais importante músico a ocupar o cargo. Não obstante, o Rio tivera mestres de capela desde bem antes de sua elevação a capital do Brasil, em 1763, e os documentos da Chancelaria da Ordem de Cristo, agora conservados na Torre do Tombo em Lisboa, dão-nos alguns poucos outros nomes ${ }^{3}$, mas principalmente uma noção da dinâmica da vida musical eclesiástica no período colonial. A conquista de Portugal, levada a efeito como uma cruzada, desde o momento em que a retomada de Jerusalém tornara-se mais improvável e apoiada em todo um ciclo medieval de peregrinação a Santiago de Compostela, teve o caráter de guerra santa em que os Cavaleiros 
Templários tiveram um papel importante e que se estenderia à conquista de outros continentes. A manutenção dos Templários em Portugal, quando a ordem foi extinta no resto da Europa, pela sua conversão em Ordem de Cristo, da qual o rei assumia a maestria, gerou uma estrutura bipartida da administração em que o rei era simultaneamente senhor do estado e governador da ordem. Assim, os mandatos deste para a constituição de, entre outras coisas, os mestres de capela das cidades nestes territórios conquistados, como foi o Brasil, encontram-se não nas Chancelarias Régias, ou nos arquivos da Igreja, mas nas Chancelarias da Ordem de Cristo ${ }^{4}$.

O primeiro mestre de capela do Rio de Janeiro de quem temos notícias foi o padre Cosme Ramos de Moraes, nomeado para a igreja matriz de São Sebastião, em 7 de junho de 1645, e, logo em seguida, Manoel da Fonseca, nomeado para a igreja de Nossa Senhora da Candelária, em 14 de novembro de 1645. O documento, que transcrevemos na íntegra (modernizando-lhe a pontuação e a acentuação, o uso de maiúsculas e minúsculas e pondo por extenso as abreviaturas), diz-nos, em meio a tantas fórmulas retóricas, algumas poucas outras coisas: que Manoel da Fonseca era clérigo do hábito de São Pedro e que o posto na Candelária já existia e estava vago, e que o Rei D. João IV o nomeia na qualidade de governador e administrador do mestrado, cavalaria e ordem de Cristo:

"Dom João, por graça de Deus Rey de Portugal e dos Algarves, d'aquém e d'além mar, em África senhor da Guiné, e da conquista, navegação, comércio da Ethiopia, Arábia, Pérsia e da Índia, etc., como govenador e perpétuo administrador que sou do mestrado, cavalaria e ordem de nosso Senhor Jesus Cristo, faço saber a vós, Doutor Antônio de Mariz Loureiro, administrador da jurisdição ecclesiástica da cidade de São Sebastião do Rio de Janeiro e mais as capitanias de sua repartição, que por hora estar vaguo o ofício de mestre da Capella da Igreja de Nossa Senhora da Candelária da mesma cidade e pella nomeação [e] boa informação, que me destes 
do padre Manoel da Fonsequa, clérigo do hábito de São Pedro, de sua suficiência, vida e custumes. Hey por bem e praz nelle o aprezentar, como com efeito aprezento e hey por aprezentado, que os servirá como cumpre ao serviço de Deus e meu; e, vos encomendo e mando, the deis a posse do dito oficio e lho deixeis servir e delle uzar, e com o dito oficio haverá o mantimento a elle ordenado e as provisões e precalços, que lhe direitamente pretenserem e esta se cumprirá, sendo passada pela chancelaria da ordem. Nicolau de Carvalho a fez, em Lisboa, aos quatroze de novembro de seiscentos e quarenta e cinco",

A carta de apresentação similar, que fora feita pouco antes a Cosme Ramos de Morais ${ }^{6}$, informava-nos que a jurisdição eclesiástica do Rio de Janeiro estendia-se às "mais capitanias da banda do sul [do Brasil]" (daí encontrarmos as nomeações para São Paulo, Santos e São Vicente, dentro do "destrito do Rio de Janeiro") e que "por hora estar vago o cargo de mestre da capella da igreja matriz de São Sebastião do Rio de Janeiro, dessa dita cidade e suas anexas, por haver muitos annos que não tem proprietário, e pela boa informação que me destes", ao padre Cosme Ramos de Morais, também clérigo do hábito de São Pedro, caberia servir "como cumpre ao serviço de Deus e bem das mesmas igrejas, enquanto vós [o doutor Antônio de Mariz Loureiro] assim o quizerdes". A ele, como a Manoel da Fonseca, cabia um ordenado fixo, "assim como até agora o houve e como houveram os mestres de capella seus antecessores". O valor aproximado deste ordenado talvez fosse semelhante àquele pago ao mestre de capela de Salvador naqueles tempos: $30 \$ 000$, trinta mil réis, que a custa de pedir e peticionar a cada três anos, havia sido concedido desde 1568 a Bartolomeu Fernandes Pires, primeiro como $10 \$ 000$ de acrescentamento ao antigo ordenado de $20 \$ 000$, e em 1590 , já depois de morto Bartolomeu Pires, fixado por alvará ${ }^{7}$.

Alguns anos mais tarde, em 10 de fevereiro de 1653, encontramos uma nova carta de apresentação, desta vez, "por hora estar 
vaguo o cargo de mestre de capella da igreja matriz dessa dita cidade e suas annexas e de todo seu destrito e recôncavo, por deixação que delle fez o padre Cosme Ramos de Morais, último possuidor que delle foi, e tendo respeito às partes e qualidades, suficiência e merecimentos (...) do padre Manoel Fonseca", vêmolo monopolizar o cargo em toda a cidade e distrito, "em o qual nenhua pessoa poderá levantar compasso sem sua licença"8.

Aparentemente, o padre Manoel Fonseca não se preocupava exclusivamente com o bom serviço de Deus e do rei, pois sua exclusividade na prática musical o levava a cobrar muito caro por seus préstimos, o que gerou, em seguida, protestos. Desta forma, em 1679 o rei exara um alvará a pedido de uma Irmandade na então distante igreja de Santa Cruz, que, pela importância, transcrevemos inteiro:

"Eu, o príncipe [Dom Pedro] etc., como Regente e Governador etc., faço saber, que havendo consideração ao que por sua petição me representaram os irmãos da Irmandade de Corpo Santo, sita na Igreja de Santa Crux da Capitania do Rio de Janeiro, em rezão de nas celebridades e festas que se fazem naquela cidade haver somente hum mestre da capella, que por ser só não consente que outrem levante o compasso em nenhua igreja, e quando lhe vão fallar para assistir nas festas querer paguarse com tanto excesso que muitas se deixam de fazer na dita igreja, o que he em deserviço do culto Divino e devoção dos fieis, que a esta concorrem com suas esmollas, por ser Irmandade pobre de forasteiros, que só vivem de sua navegação.

Hei por bem e me praz conceder licença aos ditos irmãos, que havendo músico na dita Igreja, possa este levantar o compasso e fazer as festas nella com os que chamar, e não havendo na dita Igreja, levantará o compasso qualquer outra pessoas que os Mordomos elegerem, nas quais festas, que assim fizerem se não poderá intrometer o mestre da capella, nem impedirlhas, e este meu alvará se cumpra e guarde, como nele se 
contém, que valerá como carta posto que seu effeito haja de durar mais de hum anno, sem embargo de qualquer Provizão ou Regimento em contrário e se cumprirá. Sendo passado pella chancelaria da ordem. Antonio de Oliveira de Carvalho o fez, em Lisboa, aos dezanove dias do mês de Novembro de mil e seiscentos e setenta e nove annos"'.

Parece-nos que este ânimo em quebrar um abuso de privilégio foi fundamental para a dinâmica musical da colônia. Até então, era freqüente que os próprios músicos entrassem com representações, pedindo mercê do cargo para explorá-lo com exclusividade, em todas as vilas e cidades exceto em Salvador e no Rio, onde os mestres de capela vêm apresentados pela autoridade eclesiástica. É o caso de Antônio Correa, mestre da capela da freguesia de Santo Antônio do Cabo, na capitania de Pernambuco, a quem foi dado, em 30 de julho de 1653, o cargo na igreja matriz da Vila de Olinda, "para que o exercite tanto que estiver debaixo de minha obediência, em a qual nenhua outra pessoa poderá levantar compasso senão com sua licença (...) e [por] mais de um anno sem embargo de qualquer provizão"10. É também o caso de Manoel da Motta Botelho, que pede "para servir ao cargo de mestre da capella da conquista e cidade de São Luiz do Maranhão (...)" e lhe é feita mercê por Dom Felipe de que "ninguém poderá fazer compasso nem capella em todos os teinços da dita conquista sem a sua ordem", mas com declaração ao "reverendo Dom Miguel Pereira, bispo da see da Cidade do Salvador da Bahia de Todos os Santos", de que "querendo lhe retirar, ou extinguir o dito cargo, o podereis livremente fazer, sem per isso minha fazenda lhe ficar obrigada a satisfação alguma"'l. Isto em contraste como a situação nas sés do Rio e de Salvador, onde em geral consta que os ordenados serão pagos com dinheiro "dos dizimos da dita cidade".

Mais até do que a perda da importância pecuniária que tinham as nomeações como mestre de capela e seu conseqüente desaparecimento dos registros nas Chancelarias da Ordem de Cristo, 
é possível que o sistema de arrematação da música em pregão público, nas Miras Gerais no século seguinte, que tanto chamou a atenção de Curt Lange ${ }^{12}$, em que ao contrário do privilégio que ainda gozavam os mestres de capela em Europa, um sistema extremamente moderno de contratação entre as partes interessadas, tenha tido origem nesta atitude, transmitida do Rio de Janeiro às Minas Gerais, quando faziam parte do mesmo bispado, antes da criação do Bispado de Mariana, em 1747.

Já a dignidade de chantre, o responsável pelo coro que responde nas catedrais, é obviamente sempre ocupada por um clérigo e, ainda que sua importância musical se tenha mais e mais deteriorado, com o aprofundamento da era barroca, em uma função administrativa e de prestígio e, nas celebrações, numa presença visual, enquanto o canto se profissionaliza e se amplia a função do mestre "de fazer compasso e capella", é muito provável que no século XVII, pelo exemplo que temos do repertório português, ainda preselvasse algo de sua tradição. Foi o rei Dom Pedro III a mandar erigir a dignidade de chantre no Rio de Janeiro, recomendando ao segundo bispo da cidade, Dom Joseph de Barros Marcão, que desse ao padre João Pimenta de Carvalho a posse, em vinte de janeiro de 1685 , com ordenado de $80 \$ 000$ réis por ano ${ }^{13}$. Em 1691, João Pimenta é promovido a deão da catedral ${ }^{14}$, e, em primeiro de janeiro de 1694, o padre do hábito de São Pedro, Manoel Vieira Neves, recebe a dignidade de chantre ${ }^{15}$, que mantém até sua morte. É sucedido então, em 18 de dezembro de 1727, pelo doutor Manoel de Andrade Varneque, então arcediago na mesma sé ${ }^{16}$. Após esta data, não há mais nenhuma nomeação, seja para mestre de capela, seja para chantre nas Antigas Chancelarias, dado importante se compararmos à série ininterrupta na sé da Bahiạ, que dá uma idéia clara da maior importância ali do cargo de chantre, mesmo após a transferência da capital ${ }^{17}$. Muito mais tarde, em 22 de julho de 1795, aparece nas Chancelarias da Ordem de Cristo de D. Maria I, a nomeação do padre José Pereira Duarte para chantre da Sé do Rio de Janeiro ${ }^{18}$. É porém, um tempo em que a música de igreja brasileira fazia já sua transição para o neoclassicismo grandiloqüente, e 
o estilo tradicional português onde, dentro de uma prática litúrgicomusical conservadora, o chantre mantivera um papel importante, fora sendo, desde a morte de D. João V, em 1750, abandonado ${ }^{19}$.

\section{NOTAS}

1. Ver Robert STEVENSON, "Some Porluguese Sources for Early Brazilian Music History", in Yearbook, Inter-American Institute for Musical Research, IV (1968) p. 1-43.

2. Augusto Sacramento BLAKE, Diccionario Bibliographico Brazileiro, Rio de Janeiro, Tipographia Nacional, 1883, I, p. 272.

3. Já nomeados em Sousa VITERBO, "A Ordem de Christo e a musica religiosa nos nossos domínios ultramarinos", in O Instituto Revista Scientifica e Literária, Coimbra, Imprensa da Universidade, LVII (1910), p. 13-14.

4. Não só obviamente os mestres de capela do Rio de Janeiro, mas de diversas outras cidades do Brasil colônia. Daqueles que não se perderam (é impossivel saber até que ponto são completos os livros, que representam já uma transição das cartas, provisões e alvarás), temos as seguintes nomeações:

Para a sé de Salvador da Bahia [Cernicchiaro (Storia della musica nel Brasile, p. 153), citava o nome de FRANCISCO VACCAS, cantor na catedral da Bahia em 1554, vindo do Espírito Santo, que, segundo carta de Pedro Fernandes Sardinha ao rei D. João, ofereceu-se a dar aulas no colégio dos jesuítas sob as condições de ser nomeado mestre de capela, ordenado sacerdote e posteriormente obter uma posição como canônico.] não temos a nomeação do primeiro mestre de capela de que temos notícias nas Chancelarias, BARTOLOMEU FERNANDES PIRES, apenas documentos relativos a seu ordenado (ver adiante nota 7); há, ao contrário, a mercê do cargo, pelo rei D. Felipe, em 06.07.1626, "visto o que alegou e a informação que se houve", a FRANCISCO BORGES DA CUNHA, "cavaleiro fidalgo de minha casa ... por ter as partes necessárias para servir o dito cargo de mestre de capela dessa dita sé, e [ag]ora actualmente a estar servindo de vinte annos a essa parte, por consentimento dos bispos della" (Antigas Chancelarias da Ordem de Cristo, doravante $A C h O C$, livro 12 , f. 214 v.), carta de apresentação ao mesmo, em 26.05.1628 ( $A C h O C$, livro 26, f. 173); em 05.07.1661, ao padre JOAQUIM CORREA, "natural dessa cidade", por falecimento de Francisco Borges da Cunha ( $A C h O C$, livro 47, f. 119); em 22.09.1666, a ANTONIO DE LIMA CACERES, por falecimento do Pe. Joaquim Correa ( $A C h O C$, livro 45, $\mathrm{f}$. 337); e, em 19.12.1686, ao padre frei AGOSTINHO DE SANTA MÔNI- 


\section{CA (AChOC, livro 66, f. 339);}

No manuscrito, de autoria de Domingos de Loureto Couto, pertencente à Biblioteca Nacional de Lisboa, chamado Desagravos do Brasile Glorias de Pernambuco (P-Ln Ms.B.16.23, fl. 793, citado em Ernesto Vieira, Diccionário biográphico de músicos portuguezes, transcrito in Anais da Biblioteca Nacional do Rio de Janeiro, XXIV (1902) e XXV (1903), há menção ao padre JOÃO DE LIMA, mestre de capela primeiro na Catedral da Bahia e depois na Catedral de Olinda na época do bispo D. Mathias de Figueiredo (ca. 1670-80). Vieira cita também, e nos diz haver música sua na Fábrica da Sé Patriarcal, em Lisboa, o nome de THEODORO CYRO DE SOUZA, a partir de 26.10.1681, mestre de capela na Bahia, sob o patrocínio do rei D. Pedro.

Para a igreja da Vila de Igaraçu, na Bahia, em 10.04.1629, por petição, SIMÃO FURTADO DE MENDONÇA (AChOC, livro26, f. 195).

Para as igrejas de Caxueira [ou Caxueiros], Jaguaripe [ou Guaçagipe], Itaparica [ou Taparica], Cotogipi [ou Cutugipe] (...) São Bartolomeu, Santo Amaro do Petinga [Pistanga] (é interessante a confusão das grafias em um documento oficial) e de todos os seus distritos e termos, no arcebispado da Bahia, "no qual cargo poderá levantar compasso em todas as festas que exercitar tudo o que a ele tocar, que o sirvirá como comvém ao bem das mesmas igrejas ... enquanto eu o houver por bem e não mandar 0 contrário", em 10 de abril de 1714, ao padre frei IGNÁCIO DA MADRE DE DEUS, religioso e professo do Convento do Carmo da cidade da Bahia, "por ser actualmente da capella do dito seu convento com grande aceitação de toda a religião e povo de sua cidade, cantando geralmente em todo esse estado, por ser mestre na música, e dos milhores, que exercita a dita arte" (AChOC, livro 90, f. 116).

Para a igreja da freguesia de Nossa Senhora da Conceição da Praia, $€$ suas anexas, na Bahia, em 16.12.1713, por petição a JOSÉ RIBEIRO DE BARROS, clérigo do hábito de São Pedro, "por ser mestre na música e ciente nela, e haver servido o dito cargo na referida freguesia com boa satisfação e aceitação por seu notório préstimo" ( $A C h O C$, livro 90, f. 90). Para a igreja matriz de São Luiz do Maranhão, em 18.12.1629, carta de apresentação a MANOEL DA MOTA BOTELHO $(A C h O C$, livro 26, f. 208); em 15.09.1648, JOÃO RIBEIRO LOBO ( $A C h O C$, livro 40, f. 276v.). Para a igreja matriz de Nossa Senhora das Neves da cidade da Parahiba, em 04.09.1655, carta de apresentação a DOMINGOS ALVARES FILGUEIRA ( $A C h O C$, livro 38 , f. 420).

Para a igreja matriz da Vila de Olinda, em 30.07.1653, a ANTÔNIO CORREA ( $A C h O C$, livro 41, f. 303).

Para a freguesia da Invenção da Santa Cruz, na Vila de São Jorge, da Capitania de Ilhéus, carta de confirmação, em 21.05.1719, a FRANCIS- 
CO FURTADO DE MENDONÇA ( $A C h O C$, livro 98, f. 252v.).

Para a igreja matriz da Vila de Nossa Senhora da Vitória, Espírito Santo, em 01.06.1643, ao capitão BENTO FERREIRA DE QUEIROZ ( $A C h O C$, livro 25 , f. $234 \mathrm{v}$.).

Para a Vila de Mariana, Minas Gerais, alvará de criação do posto, em 02.05.1747 ( $A C h O C$, livro 227, f. 237).

Para a Vila de São Paulo, sabiamente ainda no distrito do Rio de Janeiro, em 20.11.1661, alvará a JOSÉ DE MORAES ( $A C h O C$, livro 47, f. 179v.). Para a Vila de Santos, eñ 15.09.1669, a JOÃO DE ROIXAS MOREIRA ( $A C h O C$, livro 56, f. 235v.).

Para a igreja đe São Vicente, em 20.05.1672, a MANOEL DE AGUIAR (AChOC, livło 63, f. 51).

Curiosamente, também para a capitania de S. Vicente, encontra-se não nas Chancelarias da Ordern de Cristo, mas naquelas de Dom João IV, uma assignação para mestre de capela de Nossa Senhora da Conceição, para FRANCISCO TORRES (Chancelarias de Dom João $I V$, livro 16, $\mathrm{f}$. $94 \mathrm{v}$.) e, ao mesmo, um alvará de ordenado e para seus homens (idem, livro 22, f. 147v.). É uma particularidade certamente decorrente da forma de colonização da Capitania de São Vicente.

Para a Igreja Matriz de Nossa Senhora do Rozário, em Paranaguá, bispado de São Paulo, em 25.11.1750, carta a JOSÉ CAETANO DA CRUZ ( $A C h O C$, livro 267, f. $369 \mathrm{v}$.).

5. $A C h O C$, livro 24 , f. 458 .

6. $A C h O C$, livro 24 , f. $385 \mathrm{v}$.

7. Ver $A C h O C$, livro 1, f. 137; idem, livro 4, f. 24; idem, livro 2, f. 29v.; idem, livio 8, f. 259. Parece-nos que Bârtolomeu Pires não necessitava realmente tanto de seu ordenado, poís a llha da Maré, com "muito boa terra para canaviais é algodões, onde está um engenho de açúcar que lavra bois, que é de Bartolomeu Pires, mestre de Capela da Sé" [cfr. Gabriel Soares, cit. por Hebe Machado BRASIL, A música na cidade do Salvador, Salvador, Prefeitura Municipal, 1969, p. 57], lhe deveria prover, além do monopólio da música, é claro, sua subsistência.

8. $A C h O C$, livro 41, f. 294.

9. $A C h O C$, livto 69, f. $9 v$.

10. $A C h O C$, livito 41 , f. 403 .

11. $A C h O C$, 1 frfo 26, f. 208.

12. Francisco Curt LANGE, A organização musical durante o período colonial brasileiro, Coimbra, 1966.

13. $A C h O C$, livro 58, f. $430 \mathrm{v}$.

14. Em 29.06.1691. $A C h O C$, liviro 52, f. $202 \mathrm{v}$.

15. $A C h O C$, lívro 82, f. 5 .

16. $A C h O C$, livro 194 , f. $42 \mathrm{v}$. 
17. Há também para as outras sés brasileiras um grande número de nomeações de chantres, às quais daremos as referências depois. Vão aqui citados, com a data de suas nomeações, apenas os da Bahia, que representam o grupo mais numeroso: Pe. JERÔNIMO DA FONSECA, 26.08.1621 (AChOC, livro 22, f. 179v.); Pe. FRANCISCO GONÇALVES FAGUNDES, 19.07.1641 (AChOC, livro 36, f. 230v.); Pe. SEBASTIÃO DE BULHÕES, 03.10.1644 (AChOC, livro 24, f. 269); Pe. ANTÔNIO DA COSTA, 04.10,1653 (AChOC, livro 38, f, 38); Pe. DOMINGOS VIEIRA DE LIMA, 12.03.1661 ( $A C h O C$, livro 47, f. 59v. 38); Pe. FRANCISCO PEREIRA, 02.02.1683 (AChOC, livro 73, f. 445v.); Pe. JOÃO DE PASSOS DA SILVA, 30.11 .1698 (AChOC, livro 83, f. 101v.); Pe. MANOEL VIEIRA DE BARROS, 20.09.1709 (AChOC, livro 88. f. 98); Pe. MANOEL FERNANDES DA COSTA, 16.08.1738 ( $A$ ChOC, livro 206, f. 139v.); Pe. MANOEL DE MATTOS PEREIRA, 06.09.1754 (AChOC, livro 274, f. 134); Pe. JORGE CORREA LISBOA, 20.06.1772 (AChOC, livro 305 , f. 204v.); Pe. IGNÁCIO PINTO D'ALMEIDA, 31.03.1787 (Chancelarias da Ordem de Cristo de D. Maria I, livro 18, f. 54); e Pe. SALVADOR DA FONSECA BARBOSA, 11.03.1800 (Chancelarias da Ordem de Cristo de D. Maria I, livro 32, f. 22).

18. Chancelarias da Ordem de Cristo de D. Maria I, livro 23, f. 40v.

19. Por curiosidade, as outras nomeações de chantres no Brasil, encontradas nas Chancelarias Antigas da Ordem de Cristo são: Sé do Maranhão, alvará de criação em 11.04.1739 ( $A C h O C$, livro 206, f. 433v.); carta de apresentação ao Pe. BASÍlIO DE ALMEIDA, em 02.07.1746 (AChOC, livro 227, f. 6v.); ao Pe. JOÃO DUARTE DA COSTA, em 05.10.1763 (AChOC, livro 277, f. 140v.); Sé de Mariana, alvará de criação em 11.04.1739 (AChOC, livro 227, f. 237); ao doutor ALEXANDRE NUNES CARDOSO, em 17.09.1749 ( $A C h O C$, livro 251, f. 224). Sé de Olinda, ao licenciado FRANCISCO DA FONSECA REGO, em 18.01.1697 (AChOC, livro 60, f. 299v.). Sé do Pará, ao Pe. ANTÔNIO FRANCISCO PORTOFELIX, em 07.10.1756 ( $A C h O C$, livro 219, f. 154); ao Pe. ANTÔNIO JOSÉ DA CRUZ, em 11.02.1727 ( $A C h O C$, livro 182, f. 87). Sé de Pernambuco, ao Pe. MANOEL FERREIRA NUNES, em 19.04.1681 (AChOC, livro 73, f. 131); ao Pe. FRANCISCO MARTINS PEREIRA, em 15.04.1688 (AChOC, livro 79, f. 287); ao Pe. MANOEL DE FREITAS E BARROS, em 15.12.1715 (AChOC, livro 99, f. 124); ao Pe. ANTÔNIO PEREIRA DE CASTRO, em 27.03.1734 ( $A C h O C$, livro 101, f. 92); ao Pe. JOÃO SOARES BARBOSA, em 04.08.1747 (AChOC, livro 227, f. 301); ao Pe. MANOEL DE JESUS PEREIRA, em 04.07.1748 (AChOC, livro 235, f. 162).

Maurício Dottori é Doutor em Musicologia pela Wales University. 